\title{
Engaging Women: Addressing the Gender Gap in Women's Networking and Productivity
}

Tiffany D. Barnes, University of Kentucky

Emily Beaulieu, University of Kentucky

ABSTRACT Women earn $40 \%$ of new PhDs in political science; however, once they enter the profession, they have strikingly different experiences than their male counterpartsparticularly in the small but influential field of political methodology. For several years, the Society for Political Methodology, with support from the National Science Foundation, has attempted to address this gender gap through the Visions in Methodology (VIM) program. VIM features an annual conference that brings women together to present and discuss their research and to participate in professional-development sessions. Do programs like VIM have the desired impact? Using an original survey of political scientists, this study provides insights into the ways that bringing women together in small-group settings like VIM might facilitate networking and enhance productivity. In particular, the study finds that women who attend the VIM conference are better networked and more productive in terms of publication.

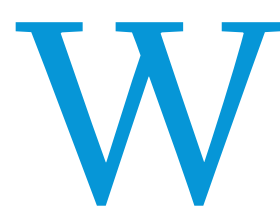

omen earn $40 \%$ of new $\mathrm{PhDs}$ in political science; however, once they enter the profession, they have strikingly different experiences than their male counterparts-particularly in the small but influential field of political methodology. Research attributes these types of differences to women's limited access to influential networks, which are crucial for developing and sustaining a productive career (Bagilhole and Goode 2001; Mathews and Anderson 2001). For several years, the Society for Political Methodology (Polmeth), with support from the National Science Foundation (NSF), has attempted to address this gender gap through the Visions in Methodology (VIM) program. VIM features an annual conference that brings women together to present and discuss their research and to participate in professionaldevelopment sessions. Do programs like VIM have the desired impact of increasing women's networking and, subsequently, their research productivity?

Using an original survey of political scientists, fielded in January 2014, we found that women who attend VIM are better

Tiffany D. Barnes is assistant professor of political science at the University of Kentucky. She can be reached at tiffanydbarnes@uky.edu.

Emily Beaulieu is associate professor of political science at the University of Kentucky. She can be reached at emily.beaulieu@uky.edu. networked than comparable men in the discipline and that they are more productive and ambitious, in terms of journal-article submissions, than women who have not attended VIM. These findings lead us to conclude that programs such as VIM are indeed an effective means of addressing the gender gap in political science.

\section{WOMEN'S EXPERIENCES IN POLITICAL SCIENCE}

Extensive research documents the different experiences of male and female political scientists. Women are less likely to obtain promotion with tenure, even after controlling for publication productivity (Hesli, Lee, and Mitchell 2012). Research in the 1990 s showed that women publish at lower rates (Young 1995); more recently, research demonstrates that the proportion of femaleauthored publications in top journals is well below the proportion of women in the discipline (Breuning and Sanders 2007; Teele and Thelen 2017). Recent studies have shown that women-after controlling for key factors (e.g., the year and venue of publication, substantive focus, theoretical perspective, methodological approach, and tenure status and institutional affiliation of an author)-are cited less often than their male peers.

Another major gender difference is that women are underrepresented in the subfield of methodology (Sedowski and Brintnall 2007). Less than $20 \%$ of papers presented at Polmeth's annual summer meeting were (co)authored by women in the past decade; 
a 2007 study found that none of the top 20 most-cited methodologists were women; and only 3\% of Polmeth's fellows are women (Dion 2014).

Given the relative influence of methodology in high-profile publications, women's underrepresentation may be particularly consequential for other aspects of their professional success. According to the 2015 Thomson Reuters Journal Citation Reports, Political Analysis-the journal produced by Polmeth-is ranked first of 161 political science journals, with an impact factor of 4.655. Furthermore, since $2001,30 \%$ of the 20 most-cited articles women's exclusion from networking opportunities with their underrepresentation in edited volumes.

\section{ADDRESSING THE GENDER GAP}

Research shows that men tend to dominate traditionally male institutions and settings; women are more likely to recognize expertise and efficacy in other women. ${ }^{1}$ Thus, small, targeted conferences for women seem to be an effective means of addressing networking issues that may be contributing to the gender gap in methodology. Programs such as CeMent in economics (Blau et al. 2010) and

\section{Given the relative influence of methodology in high-profile publications, women's underrep- resentation may be particularly consequential for other aspects of their professional success}

and $50 \%$ of the 20 most-downloaded articles in the American Political Science Review (APSR) made methodological contributions, leading Mead (2010, 454) to conclude that methodology is "perhaps the most prestigious [subfield].” Thus, women's underrepresentation in political methodology may have a negative impact on their publication rates, reduce opportunities for publication in high-profile outlets, and generally reduce their perceived prestige as political scientists.

\section{THE IMPORTANCE OF NETWORKING}

It is likely that women's differential experience in methodology is partially attributable to differences in opportunities afforded for networking between men and women (Hesli et al. 2012; Maliniak, Powers, and Walter 2013; Mathews and Andersen 2001; Mitchell et al. 2013). The networking challenges that women face may seem surprising, given that they are likely to be aware of the importance of networking (Manuel, Shefte, and Swiss 1999). Nevertheless, male-dominated social networks can provide challenges for women's incorporation into organizations, their career advancement, and their opportunities to influence policy (Barnes 2014, 2016; Franceschet and Piscopo 2014; O'Brien 2015).

Networks are fundamental for developing reputations in the discipline, increasing citation indices, and enhancing productivity (Mitchell, Lange, and Brus 2013). Hesli et al. (2012, 277) pointed out that "networks are important at tenure time because they can result in more adulatory outside reference letters." Citation counts are an increasingly important metric for promotion, and citation patterns are influenced by gender. Because women are not central to citation networks (Maliniak et al. 2013) and they are systematically underrepresented in the citations referenced by male authors and mixed-gender co-authorship teams (Mitchell et al. 2013), their citation indices, on average, lag behind their male colleagues.

Finally, networking can produce fruitful relationships for academics to receive feedback on research, develop co-authorships, and receive advice and encouragement regarding manuscript publication. Research has found that indicators of networking, such as membership association and conference attendance, are associated with increased publication productivity (Teodorescu 200o). Furthermore, Mathews and Anderson (2001, 143) identified professional networks as "...essential to initiating and sustaining publishing." At the same time, they provided evidence of
Journeys in World Politics in international relations have taken this approach-sponsoring small research conferences that facilitate networking in a women-only environment-and demonstrated their efficacy. ${ }^{2}$ A review of the CeMent program, for example, found that women who had been randomly selected to attend were publishing significantly more often-in more prestigious peer-reviewed outlets-and were securing significantly more grant funding five years after attendance (Blau et al. 2010). If VIM proves similarly successful, we expect the following results:

- Women who attend the conference should subsequently be better networked.

- The productivity of women who attend the conference should subsequently increase.

The next section evaluates these expectations using survey data collected from participants in VIM conferences and a comparable sample of nonparticipants in the discipline.

\section{VISIONS IN METHODOLOGY: NETWORKING WOMEN METHODOLOGISTS}

VIM conferences were developed through the work of Polmeth's Diversity Committee, founded in 2005. With the support of an NSF grant, seven VIM conferences had been held as of 2013.3 Two distinctive features of VIM are that (1) different institutions host the conference each year, with full autonomy over the recruitment and selection processes; and (2) it is possible for individuals to attend more than one conference. 4 The majority of attendees at the time of this survey had attended the conference only once; $19 \%$ of respondents had attended more than one conference. 5

VIM was created to provide "opportunities for scholarly progress, networking, and professional mentoring in research and teaching in order to support women in the political methodology community." " To investigate whether VIM is succeeding in improving women methodologists' networking and productivity, we fielded an online survey that targeted previous VIM participants and political scientists (both men and women) who had not attended VIM but were affiliated with the same institutions as VIM participants. Although this survey did not allow us to draw causal conclusions about the impact of VIM, we highlight and discuss interesting differences-consistent with previously stated 
expectations-between those individuals who have and have not participated in VIM.

\section{The Survey and Characteristics of the Sample}

The survey for this project was designed to collect information from individuals who potentially benefited from VIM. The focus was on their experiences with VIM as well as various being encouraged by another person. Most were encouraged by an "other mentor" (other than adviser) (6o\%) or a peer (37\%). ${ }^{13}$

Those who attended VIM mostly reported positive experiences. Figure 1 shows participants' perceptions of the utility of VIM. Of VIM participants, $67 \%$ described the experience as "useful" or "very useful"; the overwhelming majority identified networking opportunities as particularly useful.

\section{To investigate whether VIM is succeeding in improving women methodologists' networking and productivity, we fielded an online survey that targeted previous VIM participants and political scientists (both men and women) who had not attended VIM but were affiliated with the same institutions as VIM participants.}

aspects of their professional development. We also collected comparable professional-development information from a group of individuals who had not attended VIM (hereinafter referred to as the "comparison group"). We began by identifying everyone listed as presenting a paper at VIM conferences through 2014 and their institutional affiliation at the time of attendance. ${ }^{7}$ Given that most presenters were in the early stages of their career, we then formed a comparison group by identifying every assistant professor, associate professor, and $\mathrm{PhD}$ student currently on the job market from every institution that VIM participants were affiliated with at the time of participation. Excluding VIM participants, 785 individuals received e-mails to take this survey and did not select the opt-out option. Forty-five selfreported VIM participants (a group that included presenters, discussants, organizers, and attendees of the conference) ${ }^{8}$ and 243 individuals in the comparison group responded to the survey (i.e., 30.9\% of those who received e-mails and did not opt-out, non-VIM). 9

Next, we gathered information for everyone in our sample using publicly available online vitas: the individual's current rank, rank of current institution, rank of $\mathrm{PhD}$-granting institution, and number of years to obtain $\mathrm{PhD} .{ }^{10}$ Using these data and gender as predictors, we ascertained that none of the collected characteristics significantly predicted survey participation. ${ }^{11}$

\section{Who Attends VIM and What Do They Experience?}

As of 2014 , more than $80 \%$ of women who attended VIM were currently employed in tenuretrack jobs. ${ }^{12}$ Most had completed their PhDs within the past five years. The modal VIM participant reported receiving her PhD from a "Top 25" institution. When asked how they decided to apply to VIM, $76 \%$ report
Although we paraphrase to retain anonymity, the open-ended responses attested to networking as a critical component of the conference. The responses mentioned networking at VIM leading directly to professional opportunities that increased visibility, meeting mentors with whom they have regular contact, and meeting new co-authors. Indeed, $22 \%$ of those who found the conference useful also reported that if they could change something about it, they would add more opportunities to network with peers.

On balance, most VIM participants reported a positive experience and highlighted elements that are consistent with the goals of VIM, but how did they differ from the comparison group? Two key differences-experiences with networking and article-submission patterns-are notable and, in some cases, obtained conventional levels of statistical significance. However, we caution readers that it is not our intent to argue that these differences are necessarily caused by VIM because these data do not speak to causal patterns.

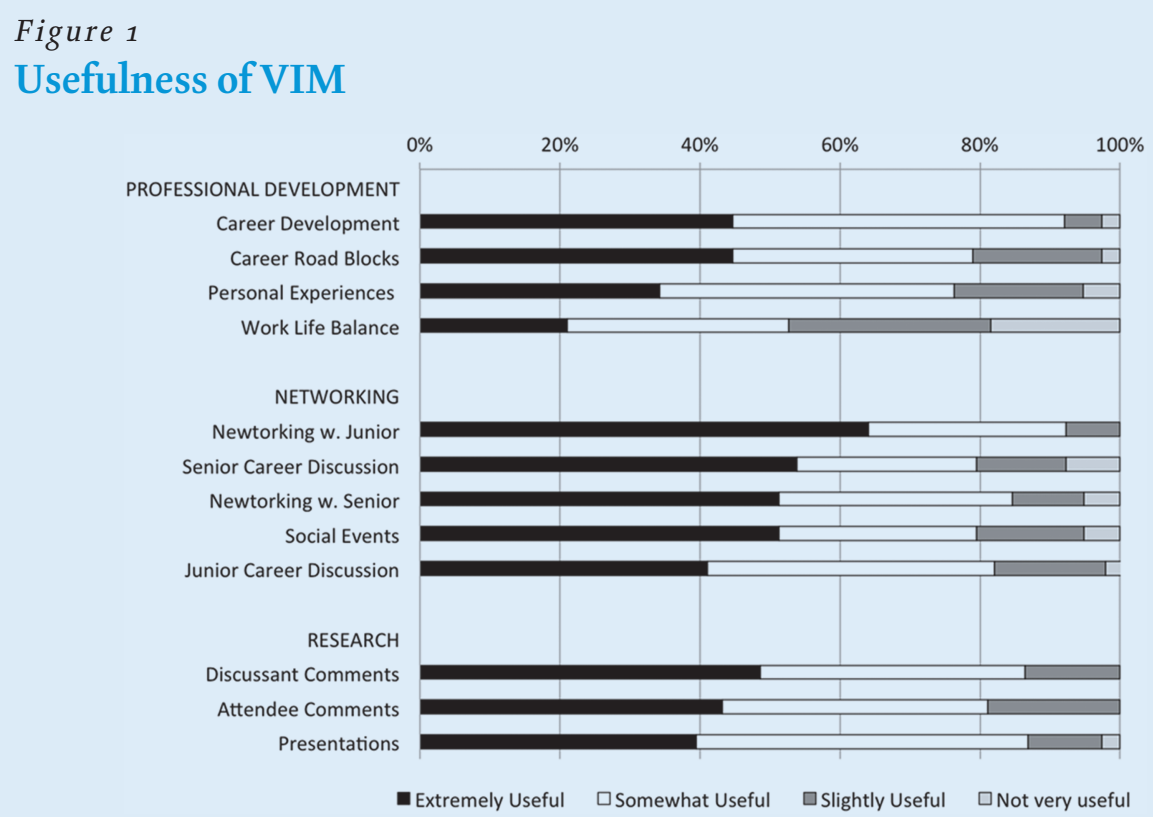

Figure 1 shows rates of perceived usefulness reported by former women VIM attendees, across a range of conference aspects and activities. For each of the Professional Development questions and the Presentations question, there are 38 responses; for the Discussant Comments and the Attendee Comments questions, there are 37 responses. For all other questions, there are 39 responses. 


\section{Networking}

Figure 2 shows that VIM participants reported mentorship at higher rates than the comparison group, and they perceived higher levels of support from peers. Given our limited ability to draw causal inference, statistical significance may be an imperfect baseline, but we offer this information nonetheless. On all three mentorship questions, the differences in reported rates between VIM participants and comparison men were statistically significant $(\mathrm{p}<0.05)$. The difference between VIM participants and comparison women was significant at $\mathrm{p}<0.05$ for the question of mentors for the year, 0.31 during their career). ${ }^{14}$ Although invited-talk rates for VIM and non-VIM women were similar, and non-VIM women, on average, gave more talks than men in our sample, there is no significant difference between non-VIM women and men. This suggests that gender alone cannot account for the difference.

Together, these results are consistent with the expectation that VIM participants may be better networked as a result of participation in the conference, developing networks outside of their department that they can draw on for advice and feedback

\section{VIM participants give invited talks at a higher rate (both annually and during the course of their career) than both comparison-group men and women.}

outside of one's own department; it approached statistical significance for the question about support from peers $(\mathrm{p}=0.094)$. Thus, in terms of mentorship, VIM participants experienced more mentorship than comparable men and were distinct from comparable women in terms of extended networks of mentorship. However, they were similar to non-VIM women in terms of identifying mentors and mentors other than an advisor.

Another indication of networking asked about in the survey is how often individuals are invited to give talks at other institutionsother than a job talk as part of an interview. VIM participants give invited talks at a higher rate (both annually and during the course of their career) than both comparison-group men and women. Nevertheless, the difference is largest when compared to men: VIM participants, on average, gave 0.48 more talks during the previous year $(\mathrm{p}=0.055)$ and 0.60 more talks during the course of their career $(\mathrm{p}=0.064)$. These differences decline when we compared only faculty; however, even among faculty, VIM participants still have given more talks, on average (i.e., difference of 0.34

\section{Figure 2}

\section{Networking and Mentorship}

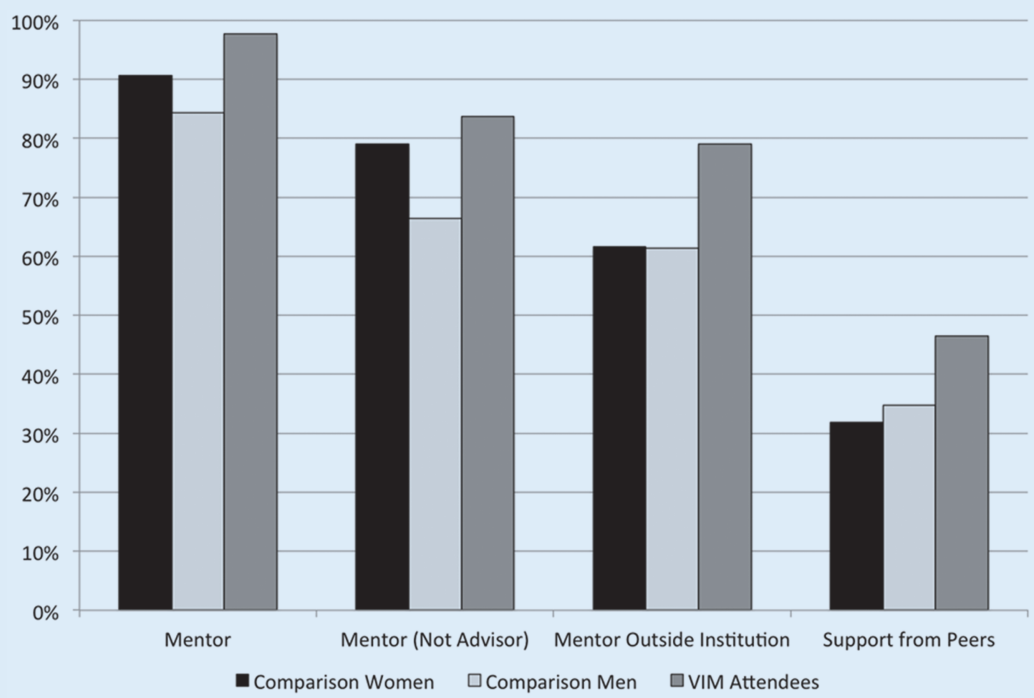

Figure 2 shows rates of survey respondents reporting perceived mentorship for three different mentor questions, as well as rates reporting that they feel "a lot" of support from peers in the discipline, categorized by VIM participation and gender within the comparison group. regarding their research. Nevertheless, we cannot eliminate the alternative possibility that an increased number of talks is not a function of VIM but rather that VIM attendance is a function of higher disciplinary visibility.

\section{Article Submissions}

When comparing average article submissions per year, we found that VIM participants exhibited higher rates than comparison-group men and women-regardless of whether graduate students were included in or excluded from the sample.15 Faculty had higher submission rates than graduate students: VIM faculty submitted 2.23 articles per year, on average, since attending VIM. Comparison-group men faculty submitted an average of 1.96 articles per year; comparison-group women faculty submitted 1.58 , on average. These differences are statistically significant only when comparing VIM to non-VIM faculty women, which indicates that VIM faculty women submitted manuscripts at rates similar to men. Men submitted more articles, on average, than comparisongroup women-although the difference was statistically significant only when participants who were not currently in tenured or tenure-track faculty positions were included in the analysis (i.e., 1.77 compared to 1.35). This suggests that, in general, there is no consistently significant difference between men's and women's submission rates. The variance in these mean rates of submission is reasonable and we have no reason to suspect that any of these averages are driven by a small number of outliers. Furthermore, although these results are comparisons of means, the patterns remain using a regression analysis, which also controls for how much time individuals report spending on book projects. 
Another consideration for productivity and career advancement is the journals that individuals target when they submit article manuscripts. Figure 3 shows the proportions of individuals who report sending manuscripts to various types of journals, based on categories presented in the survey. There is a greater tendency among VIM participants to submit to "top" outlets than among comparison-group women in particular. Indeed, consistent with the publication rates reported by Breuning and Sanders (2007) and Teele and Thelen (2017), comparison-group women are least likely to submit to one of the top three journals. ${ }^{16}$

\section{Discussion and Limitations}

Our results highlight differences between VIM participants and their peers who did not participate in VIM. These results have limitations that we want to underscore. First, some survey participants self-identified as having taken part in VIM. This means that our VIM group involved presenters, discussants, attendees, and organizers. Although the structure of VIM is designed to ensure that attendees and presenters have largely similar experiences, it is possible that there is variance in time spent at a VIM conference (e.g., presenters participated in all VIM activities, whereas attendees were more selective). This type of variance may affect the aspects that VIM participants in our survey found more or less useful. A survey that is limited to only VIM presenters or only VIM attendees may lead to substantively different results.

A second and potentially larger limitation is causal. We can interpret these differences in three possible ways. First, VIM makes a significant difference: VIM attendees expanded their networks and increased the quantity and quality of their productivity. Second, however, is that VIM participation is simply a proxy for another set of characteristics that differentiates VIM participants from the comparison group. Our survey results show, for example, that the majority of women who came to VIM typically were encouraged to apply by another person. This may suggest that the women who attend already have access to better

\section{Figure 3 \\ Targeted Journals}

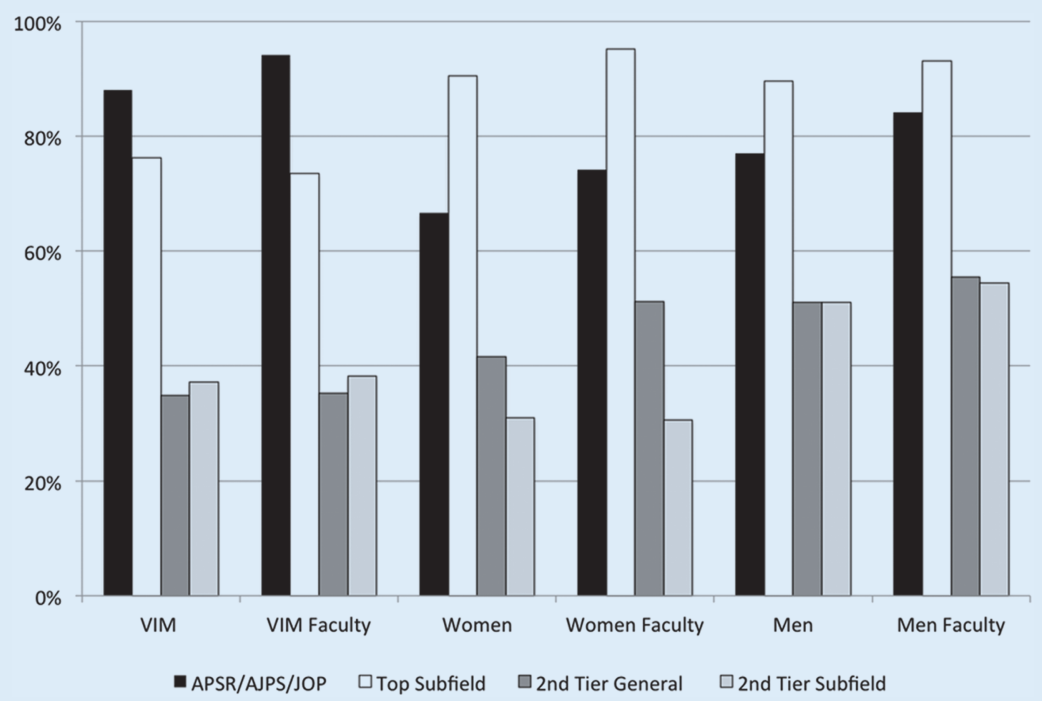

Figure 3 shows reported outlets for article submission across different survey respondents and the faculty subsets. The labels "Women" and "Men" refer to comparison-group individuals. Because individuals could select multiple outlets, the bars do not sum to $100 \%$. networks. Furthermore, the fact that they applied to VIM could be an indication of a general level of ambition that explains their differential research productivity. Third, VIM may have some effect that is difficult to quantify, given the previously mentioned selection issue.

\section{CONCLUSIONS}

This article suggests that women's differential experience in the profession may be due, in part, to a lack of access to professional networks and that programs such as VIM may increase networking opportunities for women in political methodology. Our results suggest that VIM participants find the networking component especially valuable. In particular, open-ended comments reveal that VIM participants are most enthusiastic about having a chance to interact with their peers, and this aspect of the conference has a positive impact on their publication productivity.

This study also identified differences between women who attended VIM and their peers. These effects were consistent with the effects of similar programs that relied on randomized participation to demonstrate causality. However, given that participation is not randomly assigned, we cannot know the extent to which VIM is causing these differences. Even if the association of VIM with increased research productivity and networking is not causal, however, the program can still be a valuable tool for improving women's representation in political methodology. This conference represents an important networking opportunity, which is likely beneficial even to highly networked, productive participants-and certainly to those who are less so. Furthermore, improving women's representation in methodology is critical for the substantive quality of research produced in this subfield (Achen 2014).

The value of such an initiative is most apparent in political methodology, in which women are underrepresented, but it also can be beneficial across subfields in political science-as the

Journeys program has shown in international relations. Even if the only result of initiatives aimed at closing gender gaps is to create space for some women to select an opportunity to connect, it nevertheless provides a much-needed opportunity for women to flourish in organizations and institutions where their experiences are very different from men's experiences. Ultimately, the benefits of these programs do not accrue solely to women because their flourishing within the discipline, in turn, will enhance the quality and diversity of research throughout political science.

\section{SUPPLEMENTARY MATERIAL}

To view supplementary material for this article, please visit https://doi.org/10.1017/ S1049096516003000. 


\section{ACKNOWLEDGMENTS}

The authors thank Yanna Krupnikov for her invaluable contributions to the project, including authorship of an earlier version of this article. Thanks also to Megan Shannon and Justin Esarey for publishing an earlier version of this research in The Political Methodologist. We thank Janet Box-Steffensmeir, Michelle Dion, Sona Golder, Suzanna Linn, Corrine McConnaughy, Sara Mitchell, Megan Shannon, Laura Stephenson, and Caroline Tolbert for providing information about the VIM conferences that they hosted. Michelle Dion and Sara Mitchell also provided feedback on this article, for which the authors are grateful. Our thanks to Heath Abney, Chelsea Ahting, Alexis Asamoah, Kaitlyn Cox, Michael Harr, Jordan Keeton, Marcel Roman, and Gregory Saxton for research assistance.

\section{NOTES}

1. For a more extensive discussion of this point, see Barnes $(2016,34-5)$.

2. For details on these programs, see the online appendix.

3. Three additional conferences were held since this study was conducted (i.e., 2014, 2015, and 2016); another is planned for 2017

4. See the online appendix for more details on different hosts' recruitment practices.

5. See the online appendix for more summary statistics on conference participants.

6. Available at http://visionsinmethodology.org.

7. See the online appendix for more on survey design.

8. The original number of self-identified VIM participants was 47. Of these individuals, one identified as male later in the survey. Although men are welcome to attend all research presentations that are part of VIM, they are asked to leave the professional-development sessions and they do not participate in the networking opportunities. Because men do not participate in large components of the conference, the male self-reported VIM participant was excluded from all VIM analyses and comparisons. Another person identified as a VIM participant but did not show evidence of answering any VIM-focused questions later in the survey. This left 45 self-identified VIM participants who did not identify as male and who at least saw the VIM-focused question. Two of these participants saw but did not answer the gender question later in the survey; we used the open-ended questions to confirm that these participants identified as women.

9. See the online appendix for more on survey participation and response rates. In particular, we discuss the potential peculiarity of the VIM sample. Although we targeted the presenters with a specific invitation, our comparison sample also captured people who had attended VIM without presenting (and therefore were not listed on some conference programs). Because the VIM survey is based on self-reported participation, our VIM sample included those deliberately targeted as presenters and those who had attended.

10. Rank information is based on the most recent rankings from US News $\mathcal{E}$ World Report, which covers the top 86 political science doctoral programs in the country.

11. See the online appendix for the full regression table.

12. Note that "tenure-track jobs" include individuals who already have tenure.

13. See the online appendix for the full text of the survey.

14. Here, "faculty" means individuals in tenure-track or tenured positions.

15. See the online appendix for the method used to calculate averages.
16. The categories offered here referenced only the American Political Science Review, American Journal of Political Science, and Journal of Politics as "top 3 general journals." The choice among other categories reflected individuals subjective understanding of subfield journal rankings, as well as what constitutes second-tier general journals.

\section{REFERENCES}

Achen, Christopher H. 2014. "Why Do We Need Diversity in the Political Methodology Society?" The Political Methodologist 21 (2): 25.

Bagilhole, Barbara and Jackie Goode. 2001. "The Contradiction of the Myth of Individual Merit, and the Reality of a Patriarchal Support System in Academic Careers: A Feminist Investigation." European Journal of Women's Studies 21 (8): 161-8o.

Barnes, Tiffany D. 2016. Gendering Legislative Behavior: Institutional Constraints and Collaboration. New York: Cambridge University Press.

- 2014. "Women's Representation and Legislative Committee Appointments: The Case of the Argentine Province." Revista Uruguaya de Ciencia Politica 23 (2): 135-63.

Blau, Francine, Janet M. Currie, Rachel T. A. Coroson, and Donna K. Ginther. 2010. "Can Mentoring Help Female Assistant Professors? Interim Results from a Randomized Trial.” National Bureau of Economic Research Working Paper 15707.

Breuning, Marijke and Kathryn Sanders. 2007. "Gender and Journal Authorship in Eight Prestigious Political Science Journals." PS: Political Science E Politics $40(2): 347-51$.

Dion, Michelle. 2014. “An Effort to Increase Women's Participation: The Visions in Methodology Initiative." The Political Methodologist 21 (2): 6.

Franceschet, Susan and Jennifer Piscopo. 2014. "Sustaining Gendered Practices? Powe and Elite Networks in Argentina." Comparative Political Studies 47 (1): 86-111.

Hesli, Vicki L., Jea Mook Lee, and Sara McLaughlin Mitchell. 2012. "Predicting Rank Attainment in Political Science: What Else Besides Publications Affects Promotion?" PS: Political Science and Politics 45 (3): 475-92.

Maliniak, Daniel, Ryan Powers, and Barara F. Walter. 2013. "The Gender Citation Gap in International Relations." International Organization 67 (4): 889-922.

Manuel, Tiffany, Susan Shefte, and Deborah Swiss. 1999. Suiting Themselves: Women's Leadership Styles in Today's Workplace. Cambridge, MA: Radcliffe Public Policy Institute and the Boston Club.

Mathews, Lanethea and Kristi Anderson. 2001. "A Gender Gap in Publishing? Women's Representation in Edited Political Science Books." PS: Political Science \& Politics 34 (1): 143-7.

Mead, Lawrence M. 2010. "Scholasticism in Political Science." Perspectives on Politics 8 (2): 453-64.

Mitchell, Sara McLaughlin, Samantha Lange, and Holly Brus. 2013. "Gendered Citation Patterns in International Relations Journals." International Studies Perspectives 14 (4): 485-92.

O’Brien, Diana Z. 2015. "Rising to the Top: Gender, Political Performance, and Party Leadership in Advanced Articles Industrial Democracies." American Journal of Political Science 59 (4): 1022-39.

Sedowski, Leanne and Michael Brintnall. 2007. "Data Snapshot: The Proportion of Women in the Political Science Profession." American Political Science Association. Available at http://apsanet3b.inetu.net/imgtest/Website brief on women in PS v2 1 2007.pdf.

Teele, Dawn L. and Kathleen Thelen. 2017. "Gender in the Journals: Publication Patterns in Political Science.” PS: Political Science \& Politics, Forthcoming.

Teodorescu, Daniel. 200o. "Correlates of Faculty Publication Productivity: A Cross-National Analysis.” Higher Education 39 (2): 201-22.

Young, Cheryl D. 1995. "An Assessment of Articles Published by Women in the 15 Top Political Science Journals." PS: Political Science \& Politics 28 (3): 525-33. 